\title{
Application of ERPs neuromarkers for assessment and treatment of a patient with chronic crossed aphasia after severe TBI and long-term coma - Case Report
}

\author{
Marzena Chantsoulis', Paweł Półrola², Jolanta Góral-Półrolaㄹ , Anna Hajdukiewicz ${ }^{3}$, Jan Supiński ${ }^{4}$, \\ Juri D. Kropotov ${ }^{5}$, Maria Pachalska ${ }^{6,7}$ \\ ${ }^{1}$ Academy of Physical Education, Department of Physiotherapy, Wroclaw, Poland \\ 2 Jan Kochanowski University in Kielce, Faculty of Medicine and Health Sciences, Kielce, Poland \\ ${ }^{3}$ Old Polish University, Kielce, Poland \\ ${ }^{4}$ Academy of Physical Education, Department of Psychology, Wroclaw, Poland \\ ${ }^{5}$ Laboratory for Action Programming Neurobiology, Institute of the Human Brain, Russian Academy of Sciences, \\ St. Petersburg, Russia \\ ${ }^{6}$ Chair of Neuropsychology and Neurorehabilitation, The Andrzej Frycz Modrzewski Krakow University, Krakow, Poland \\ ${ }^{7}$ Center of Cognition and Communication, New York, NY, USA \\ Chantsoulis M, Półrola P, Góral-Półrola J, Hajdukiewicz A, Supiński J, Kropotov JD, Pachalska M. Application of ERPs neuromarkers for \\ assessment and treatment of a patient with chronic crossed aphasia after severe TBI and long-term coma - Case Report. Ann Agric Environ \\ Med. 2017; 24(1): 141-147. doi: 10.5604/12321966.1232770
}

\section{Abstract}

Objective. The study aimed to evaluate the application of ERPs neuromarkers for the assessment and treatment of a patient with chronic crossed aphasia after severe TBI and a long-term coma.

Case report. An ambidextrous female patient, aged 29, suffered from posttraumatic chronic crossed aphasia, severe $\mathrm{TBI}$ and a prolonged coma after a car accident. The patient took part in two differentiated rehabilitation programmes of neurotherapy included 20 sessions of relative beta training and 20 sessions of rTMS; both programmes were combined with behavioural training. The patient was tested 3 times: before the experiment, after completion of programme A, and after completion of programme B.

Results. In the $1^{\text {st }}$ recording, the neuromarker of aphasia was found - an excess of the P2 wave over the left temporal area. There was a cognitive control deficit - an excess of omission errors and an increase of RT variability - all indexes of sporadic ADHD. In the $2^{\text {nd }}$ recording, slight improvements in cognitive control, and language functions were found. In the $3^{\text {rd }}$ recording, after the rTMS sessions most of her cognitive dysfunctions had been resolved, including language functions. It should be stressed that the activation (especially the increase in the ERP potential of the right side over the frontal lobe) was found. The neuromarker of aphasia did not change, only the location had slightly moved frontally.

Conclusions. The application of ERP neuromarkers assists in the diagnosis, treatment, and academic success of an ambidextrous patient with chronic posttraumatic aphasia and sporadic ADHD. ERPs can be used to assess the functional brain changes induced by neurotherapeutical programmes.

\section{- Key words}

cognitive control, emotional control, relative beta training, rTMS, microgenetic theory

\section{INTRODUCTION}

Traumatic brain injury (TBI) is a worldwide public health problem[1]. According to the WHO (2000), by the year 2020, TBI will be the major cause of death and disability. There are an estimated 10 million people affected annually by TBI, due to which the burden of mortality and morbidity is increasing [2]. Over recent decades, improvements in acute care have resulted in higher survival rates. Unfortunately, the majority of survivors of moderate and severe TBI have chronic neurobehavioural sequelae, including cognitive deficits, and aphasia, as well as changes in personality and increased rates of psychiatric illness [3].

In world literature on the subject there are many articles describing the initial and persistent cognitive deficits, which

Address for correspondence: Jolanta Góral-Półrola, The Old Polish University, Kielce, Poland

E-mail: jgp@stsw.edu.pl

Received:20 July 2016; accepted: 25 October 2016; first published on February 2017 are the most common post-TBI complaints [4] and a major hindrance to normalization in the areas of independent living, social re-adaptation, family life, and vocational undertakings $[5,6]$. Several cognitive domains are predictably impaired, including frontal executive functions (problem solving, set shifting, impulse control, self-monitoring) $[7,8]$ attention $[9,10]$, short-term memory and learning $[11,12]$, the speed of information processing $[13,14]$, speech and language functions [15-16], and other special syndromes such as blindsight, neglect, prosopagnosia, and apraxia [15]. However, it should be noted that these are not completely independent domains, and that typically there is a mixture of deficits of varying degrees across domains $[4,8,17]$.

Aphasia it is a common complication that affects many individuals with TBI. However, aphasia treatment continues to be a hot topic among researchers. Treatment advances in aphasia are also increasing, and are not only directed at improving speech and language itself [17]. Conventional speech-language therapy for aphasia has been a feature of 
rehabilitation medicine for many decades. Psychological and neuropsychological aphasia consultations are more recent but established facets of ongoing patient care. Pharmacological interventions to help manage aphasia continue to be investigated, including the medications donepezil and bromocriptine. However, all those traditional therapies for functional brain recovery post-traumatic brain injury are still not satisfactory for patients with aphasia $[18,19]$. Todate, the best approach seems to be intensive physical and cognitive therapy $[17,20,21]$. One of the more exciting aspects of this treatment to emerge is the extension of intervention beyond the clinical setting into real-life social environments to which the patients return to after discharge from acute hospitalization and rehabilitation. However, the results are limited and the functional gains often minimal $[17,22$, $23,24,25,26]$. Therefore, adjunct interventions that can augment the response of the brain to the behavioural and cognitive training employed might be useful to enhance therapy-induced recovery in TBI patients. In this context, neurofeedback self-regulation and non-invasive brain stimulation appear to be options as additional interventions to standard physical therapies [23].

Two non-invasive methods of injecting electrical currents into the brain have proved promising for inducing longlasting plastic changes within the motor systems: transcranial magnetic stimulation (TMS) $[27,28]$ and transcranial direct current stimulation (tDCS) [29]. These techniques represent powerful methods for priming cortical excitability for subsequent motor or cognitive training; thus, their combined use can optimize the plastic changes induced by motorcognitive practice, leading to more remarkable and longlasting clinical gains in rehabilitation [28].

The presented study examines the effectiveness of neurotherapy for a patient with aphasia syndrome after severe TBI and a long-term coma. It was hypothesized that there would be a limited response to relative beta training, and a good response to rTMS, applied to regulate the dynamics of brain function.

According to the guidelines of the Helsinki Declaration (2008), the patient who participated in the experimental treatment was informed in detail about the test procedure, and subsequently provided written consent for participation in the project. The study protocols received ethical approval

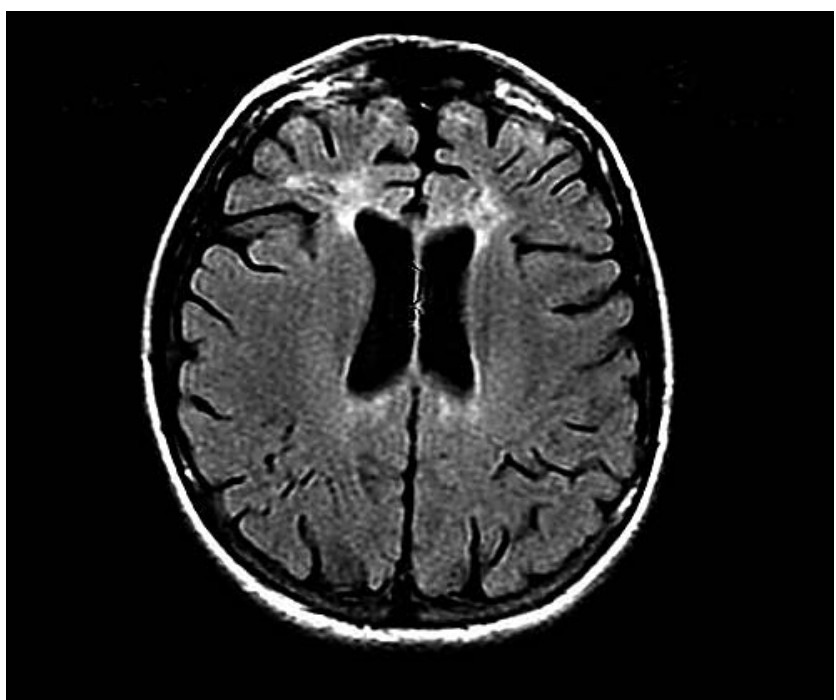

from the Ethical Committee of the Regional Medical Chamber (KB6/16).

\section{CASE REPORT}

An ambidextrous female patient, aged 29, was involved in a car accident as a consequence of which she suffered polytrauma, and remained in a prolonged coma for 2 months. She was diagnosed with severe TBI, right-side paresis and chronic posttraumatic aphasia, rendering her unable to function independently in many everyday-life situations. Post-traumatic amnesia lasted for 28 days. After awakening from the coma, she did not remember the accident nor was she able to recognize her parents and fiancé. Of note is the fact that the patient first and quickly recognized her boyfriend, reacting emotionally to him, hugging him, bursting into tears, and did not want to let him go.

After discharge from hospital, she complained of hearing loss in the right ear, something that was not confirmed in an audiogram; she was simply unable to understand speech, and was diagnosed with predominantly moderate sensory aphasia.

A brain MRI scan showed gliotic post-traumatic changes in the frontal lobes (the largest in the right hemisphere) (Fig. 1). Along the temporal lobes, fairly numerous small haemorrhagies were found. The changes in the brain increased with time and were more prominent in 2010.

Next, a brain MRI scan showed gliotic post-traumatic changes in the frontal lobes which were more prominent than in 2010, especially in the right hemisphere, with atrophy of brain parenchyma (external porencephaly) (Fig. 2).

Gliotic posttraumatic changes in the frontal lobes, especially in the right hemisphere, more prominent than in 2010, with atrophy of brain parenchyma (external porencephaly).

The patient was admitted to a rehabilitation centre and took part in a comprehensive programme of rehabilitation, including speech therapy. After 2 months she was referred to an outpatient rehabilitation unit and after one year of treatment she had achieved only a small improvement in motor functions and the ability to speak. The reduced ability to understand spoken language limited the patient in

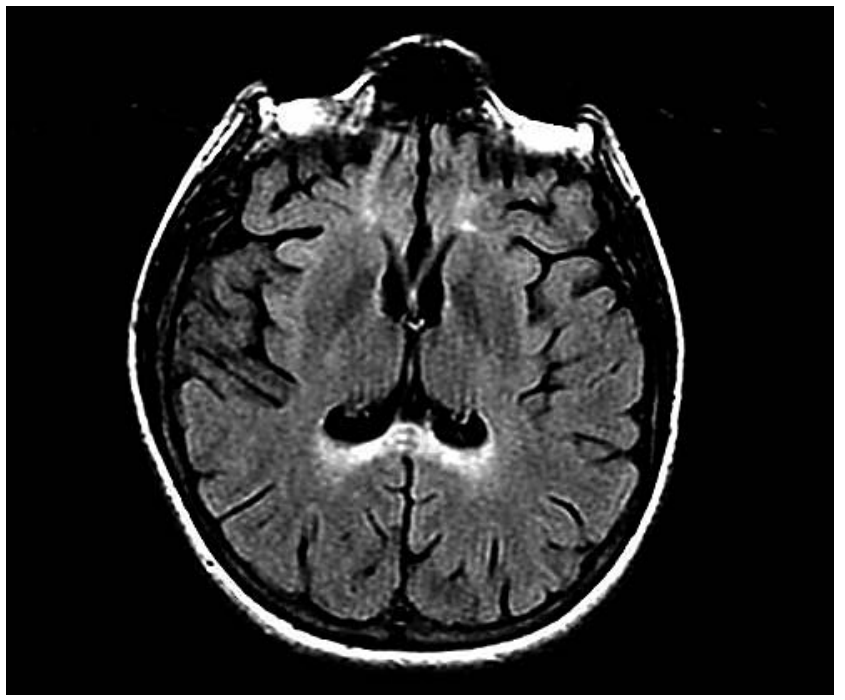

Figure 1. Brain MRI. 2010. FLAIR and frFSET2 sequences, axial plane. Gliotic posttraumatic changes in the frontal lobes (greatest in the right hemisphere) 


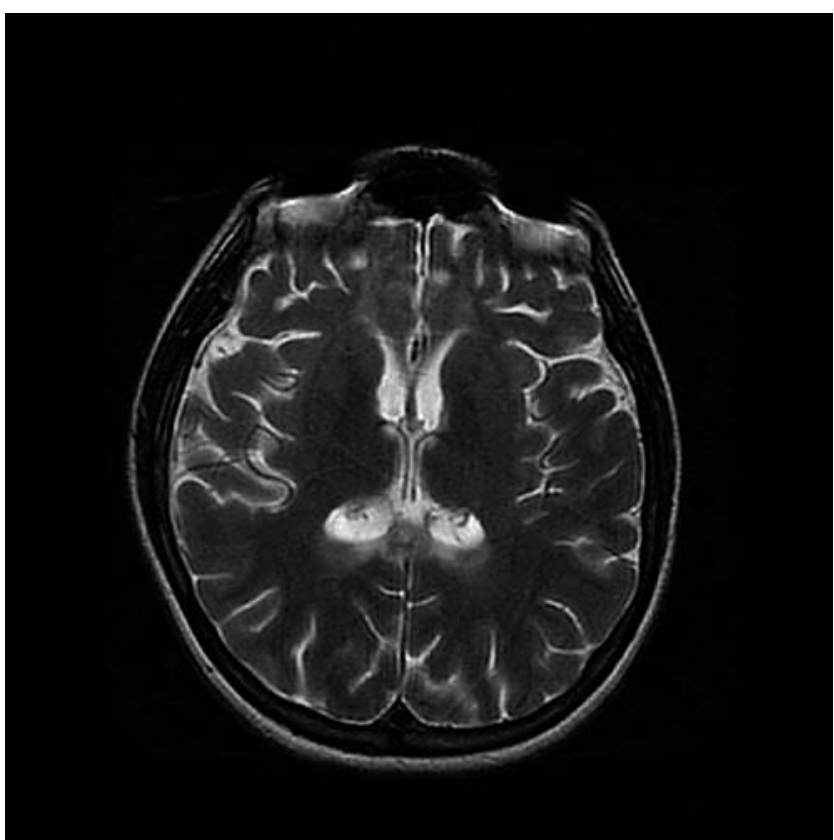

Figure 2. Brain MRI. 2011. FrFSET2 and FLAIR sequences, axial plane

daily living situations. In cases of a lack of comprehension, she behaved like a small child, protesting and reacting aggressively in situations in which her parents devoted attention to her baby sister.

As time passed, the patient developed other symptoms which isolated her from friends because she did not understand social situations. For example, in situations of social confrontations she reacted aggressively; for instance, when preparing herself for a walk with a friend in winter, and having dressed herself inappropriately in a light dress, upon being asked to change her clothes she resorted to force (kicking, beating and spitting). Additionally, she developed a defence mechanism and reacted in everyday life situations by using the word 'No'. She also presented florid confabulations, describing in multicolour situations which had not happened in reality, e.g., saying that her father was a heavy drinker, which was not the case.

The patient was admitted to a reintegrative and training centre where she participated in neuropsychological diagnosis and treatment.

Neurotherapy programme. The patient took part in 2 differentiated rehabilitation programmes of neurotherapy in crossover design:

1. Programme A - administered in 2 modules:

a) Module 1 - 20 sessions of relative beta training, the aim of which was to activate the frontal cortex by enhancing beta activity recorded over the frontal electrodes. More precisely, the electrodes were placed at $\mathrm{Fz}$ and $\mathrm{Cz}$ for bipolar recording. The procedure increased the ratio of beta EEG power/EEG power in theta and alpha frequency bands. The beta frequency band was from $13-21 \mathrm{~Hz}$, and the combined theta and alpha frequency bands were from $4-12 \mathrm{~Hz}$. Each session included approximately 20 min. of neurofeedback training [24].

b) Module 2-20 sessions of behavioural training combined with relative beta training (the procedure is described in more detail in Pachalska, Kaczmarek \& Kropotov [17]).

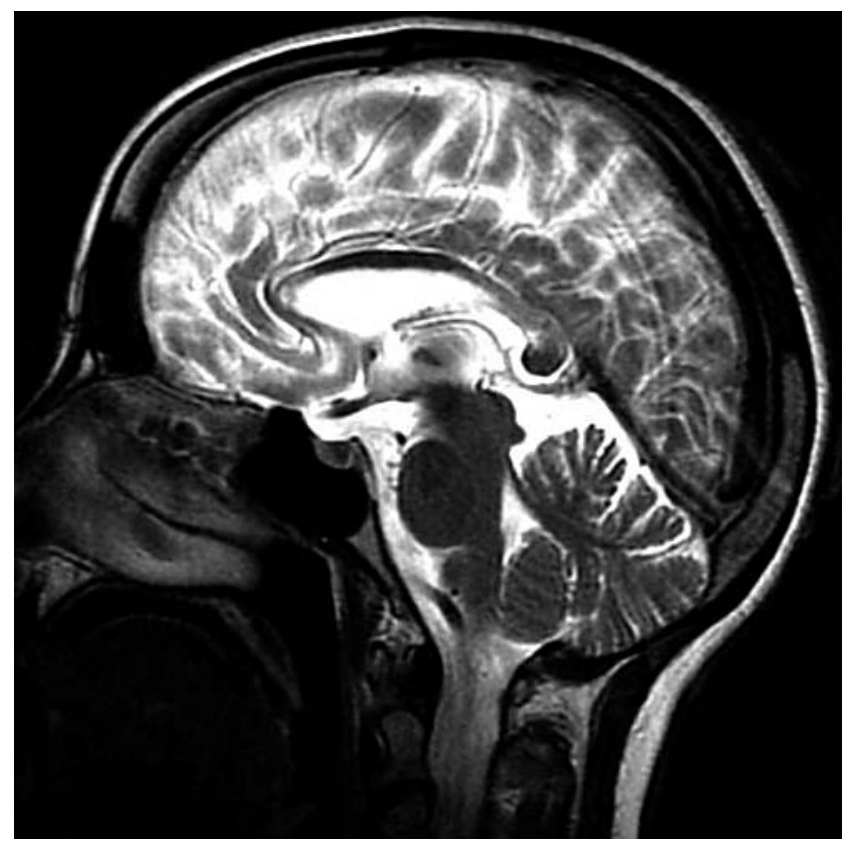

2. Program B - administered in 2 modules:

a) Module 3 - repetitive transcranial magnetic stimulation (rTMS), which is a non-invasive brain stimulation technique that modulates cortical activity $[25,26]$. During rTMS, a fluctuating magnetic field is used to induce an electrical current discharged through a coil held to the scalp over the brain region of interest. The magnetic field penetrates the scalp over this specific region of the brain. The magnetic field also penetrates the skull and induces a depolarizing electrical current in the underlying cortical surface. Repetitive strings of stimulation at a given frequency can either decrease (low frequency TMS) or enhance (high frequency TMS) the excitability of the underlying cortical areas [for review, see 16]. 20 sessions of rTMS intervention (25 repetitions) with low frequency rTMS $(1 \mathrm{~Hz})$ were used to reduce the excitability of the left frontal and temporal brain regions, and high frequency $(5 \mathrm{~Hz})$ to stimulate the right frontal and temporal brain regions. This was based on functional imaging studies of the patient's brain, suggesting that over-activation of the left frontal and temporal cortices may reduce the recovery potentials by inhibiting (perilesional) the right frontal and temporal areas.

b) Module 4-20 sessions of behavioural training combined with rTMS intervention (the procedure is described in more detail in Pachalska 2008 [14]).

The therapy was administered by the same team of therapists. Neuropsychological testing as well as ERPs was used before the entire experiment, and after the completion of programme A and after the completion of programme B.

Neuropsychological testing - Cognitive functions, including language. Neuropsychological testing in the $1^{\text {st }}$ examination showed multiple cognitive deficits (Tab. 1). The patient also showed a low Aphasia Quotient, as well as a low Cortical Quotient in the Western Aphasia Battery. She obtained the lowest data in the Token Test, recording 49 errors out of a possible 50; this means that she displayed 
Table 1. Neuropsychological testing of the patient in examinations 1,2 and 3

\begin{tabular}{|c|c|c|c|}
\hline Measure & Exam. 1 & Exam. 2 & Exam. 3 \\
\hline \multicolumn{4}{|l|}{ WAIS-R [1] } \\
\hline IQ - Full & $61.5 / 100$ & $64.5 / 100$ & $94.5 / 100$ \\
\hline IQ - Verbal & $65.5 / 100$ & $69.5 / 100$ & $99.5 / 100$ \\
\hline IQ - Nonverbal & $57.5 / 100$ & $61.5 / 100$ & $89.5 / 100$ \\
\hline \multicolumn{4}{|l|}{ WMS-III [2] } \\
\hline Attention - Spatial Span & 3 (1 $1^{\text {st }} \%$ ile $)$ & 3 (1 $1^{\text {st }} \%$ ile $)$ & 12 ( $75^{\text {th }} \%$ ile) \\
\hline \multicolumn{4}{|l|}{ Visuospatial Ability } \\
\hline WAIS-III - Block Design & 3 (1 $1^{\text {st }} \%$ ile) & 3 (1 $1^{\text {st }} \%$ ile) & 8 (25 \%ile) \\
\hline \multicolumn{4}{|l|}{ Logical Memory } \\
\hline $\begin{array}{l}\text { WMS-III - Immediate } \\
\text { logical memory }\end{array}$ & $5 / 24$ & $7 / 24$ & $20 / 24$ \\
\hline $\begin{array}{l}\text { WMS-III - Delayed logical } \\
\text { memory }\end{array}$ & $3 / 24$ & $4 / 24$ & $18 / 24$ \\
\hline $\begin{array}{l}\text { WMS-III - Immediate visual } \\
\text { recall }\end{array}$ & $9 / 41$ & $12 / 41$ & $37 / 41$ \\
\hline $\begin{array}{l}\text { WMS-III - Delayed visual } \\
\text { recall }\end{array}$ & $4 / 41$ & $6 / 41$ & $26 / 41$ \\
\hline \multicolumn{4}{|l|}{ Verbal memory } \\
\hline $\begin{array}{l}\text { CVLT - Short Delay Free } \\
\text { Recall }\end{array}$ & $0 / 9\left(<1^{\text {st }} \%\right.$ ile $)$ & $1 / 9$ & $2 / 9$ ( $<1^{\text {st }} \%$ ile $)$ \\
\hline CVLT - Long Free Recall & $0 / 9\left(<1^{\text {st }} \%\right.$ ile $)$ & $0 / 9\left(<1^{\text {st }} \%\right.$ ile $)$ & $2 / 9$ (<1 $1^{\text {st }} \%$ ile $)$ \\
\hline $\begin{array}{l}\text { CVLT - Long Delay Cue } \\
\text { Recall }\end{array}$ & Discontinued & $0 / 9$ (<1 \%ile) & $2 / 9\left(<1^{\text {tt }} \%\right.$ ile $)$ \\
\hline
\end{tabular}

\section{Executive Functions - TMT [3]}

\begin{tabular}{|c|c|c|c|}
\hline TMT- Number Sequencing & Discontinued & 150 s. (<1 \%ile) & $54 \mathrm{~s} .\left(10^{\text {th }} \%\right.$ ile $)$ \\
\hline $\begin{array}{l}\text { TMT- Number Letter } \\
\text { Sequencing }\end{array}$ & Discontinued & 150 s. (<1 \%ile) & 145 s. $\left(<1^{\text {st }} \%\right.$ ile $)$ \\
\hline \multicolumn{4}{|l|}{ Stroop } \\
\hline Colour & 90 s. $\left(<1^{\text {st }} \%\right.$ ile $)$ & 87 s. (<1 $1^{\text {st }} \%$ ile $)$ & 41 s. (16 $6^{\text {th }} \%$ ile $)$ \\
\hline Word & Discontinued & 29 s. (25 th \%ile) & 42 s. (63 $\%$ ile) \\
\hline Interferences & Discontinued & 126 s. $\left(<1^{\text {th }} \%\right.$ ile $)$ & $118 \mathrm{~s} .\left(<1^{\text {th }} \%\right.$ ile $)$ \\
\hline \multicolumn{4}{|l|}{ WCST } \\
\hline Categories & $0\left(2-5^{\text {th }} \%\right.$ ile $)$ & $0\left(2-5^{\text {th }} \%\right.$ ile $)$ & 2 (>16 $6^{\text {th }} \%$ ile) \\
\hline Perseverative Errors & $46\left(<1^{\text {th }} \%\right.$ ile $)$ & $45\left(<1^{\text {th }} \%\right.$ ile $)$ & 19 (37 \% $\%$ ile) \\
\hline $\begin{array}{l}\text { Conceptual Level } \\
\text { Responses }\end{array}$ & Discontinued & $63\left(<19^{\text {th }} \%\right.$ ile $)$ & 48 (45 $5^{\text {thoile})}$ \\
\hline Fail to Maintain Sets & Discontinued & $4\left(2-5^{\text {th }} \%\right.$ ile $)$ & $4\left(2-5^{\text {th }} \%\right.$ ile $)$ \\
\hline \multicolumn{4}{|c|}{ Language functions - WAB [4] } \\
\hline$W A B-A Q$ & 21.0 & 37.0 & 93.0 \\
\hline$W A B-C Q$ & 36.0 & 63.0 & 97.0 \\
\hline Token Test & $49 / 50$ & $39 / 50$ & $2 / 50$ \\
\hline $\begin{array}{l}\text { Boston Naming Test- } \\
\text { revised }\end{array}$ & $11 / 60$ & $39 / 60$ & $58 / 60$ \\
\hline MMSE & $12 / 30$ & $19 / 30$ & $28 / 30$ \\
\hline
\end{tabular}

[1] WAIS - R Wechsler Adult Intelligence Scale [2] WMS-III - Wechsler Memory Scale - III [3] MT $=$ Trial Making Test

Level of performance corresponding to percentiles:

$98-99 \%$ ile - Highly Superior

91-97\%ile - Superior

$75-90 \%$ ile - High Average

$75-90 \%$ ile - High Avera

$25-74 \%$ ile - Average

$9-24 \%$ ile - Low Avera

2 - 2 \%ile - Borderline

[4] WAB -Western Aphasia Battery:

$A Q$ - Aphasia Quotient

$\mathrm{CQ}$ - Cortical Quotient sensory aphasia. However, the patient also had word finding problems, which was illustrated in the Boston Naming Test - Revisited. The patient named only 11 pictures out of the possible 60 . After completing programme A of neurotherapy (relative beta training), she improved slightly in all the tested parameters. This concerns cognitive functions as well as language functions. After completing programme B of neurotherapy [repetitive transcranial magnetic stimulation (rTMS)], most of her cognitive dysfunctions were resolved, including language functions (Tab. 1). The results obtained by the patient were close to the norm.

After the second programme, the patient was able to succeed academically and finished college with only a little support (helping her to create and manage a colour-coded schedule of her responsibilities).

Table 2. Neurophysiological testing - Behaviour

\begin{tabular}{lcccc}
\hline & Omiss & Comm & RT & varRT \\
\hline P value for the $3 \mathrm{rec}$ & 0.63 & 0.60 & 0.33 & 0.90 \\
\hline $1 \mathrm{rec}$ & $88 \%$ & $0 \%$ & $366 \mathrm{~ms}$ & $35.2 \mathrm{~ms}$ \\
\hline $2 \mathrm{rec}$ & $4 \%$ & $2 \%$ & $286 \mathrm{~ms}$ & $5.7 \mathrm{~ms}$ \\
\hline $3 \mathrm{rec}$ & $4 \%$ & $0 \%$ & $336 \mathrm{~ms}$ & $10.2 \mathrm{~ms}$ \\
\hline Norms & $2.5 \%$ & $0.7 \%$ & $420 \mathrm{~ms}$ & $9.8 \mathrm{~ms}$ \\
\hline
\end{tabular}

In the first recording, behaviour was fairly deviant from the average. The subject was extremely inattentive $(88 \%$ of omission errors) and inconsistent in response (error of the variance of response was $35.2 \mathrm{~ms}$, compared to $9.8 \mathrm{~ms}$ for the healthy controls of the same age). Behaviour was normalized in the second recording and remained at the same level during the third recording.

Event Related Potentials (ERPs). Event related potentials (ERPs) were used to assess the functional changes in the patient induced by the rehabilitation programmes. This approach was used for the following reasons:

1) ERPs have a superior temporal resolution (on the order of milliseconds) among other imaging methods, such as fMRI and PET (which have a time resolution of 6 seconds and more) [21];

2) ERPs have been proven to be a powerful tool for detecting changes induced by neurofeedback training in children with ADHD $[22,23]$;

3) in contrast to spontaneous EEG oscillations, ERPs reflect stages of information flow within the brain [21, $22,24]$.

The diagnostic power of ERPs has been enhanced by the recent emergence of new methods of analysis, such as Independent Component Analysis (ICA) and Low Resolution Electromagnetic Tomography (LORETA) [21].

A modification of the visual two-stimulus GO/NO GO paradigm was used (Fig. 8). Three categories of visual stimuli were selected:

1) 20 different images of animals, referred to later as ' $A$ ';

2) 20 different images of plants, referred to as ' $P$ ';

3) 20 different images of people of different professions, presented together with an artificial 'novel' sound, referred to as 'H+Sound'. 
All visual stimuli selected were similar in size and luminosity. The randomly varying novel sounds consisted of five 20-ms fragments filled with tones of different frequencies

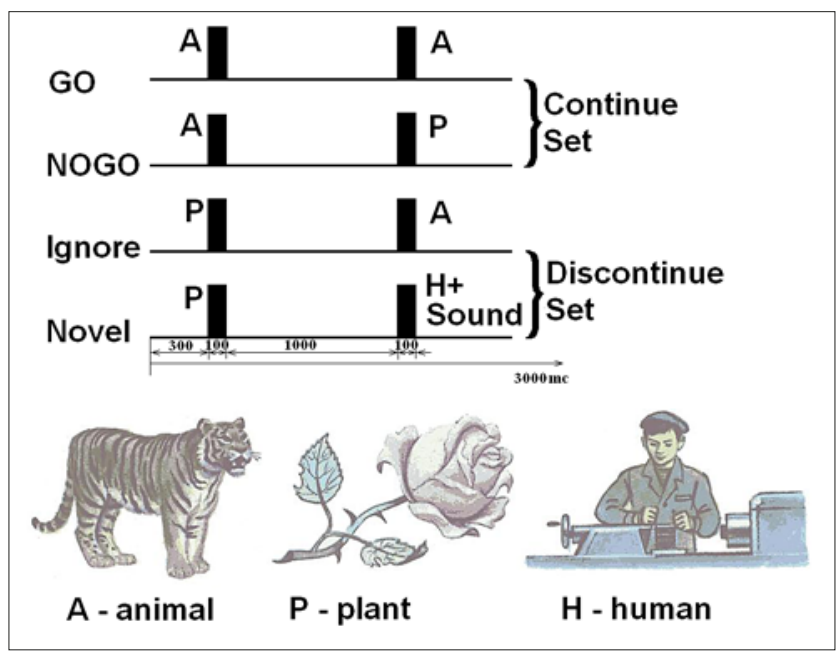

$(500,1,000,1,500,2,000$, and 2,500 Hz). Each time, a new combination of tones was used, while the novel sounds appeared unexpectedly (the probability of appearance being $12.5 \%)$.

Figure 3. Schematic representation of the 2 cued GO/NOGO task. From top to bottom: time dynamics of stimuli in 4 categories of trials. Abbreviations: $A, P, H$ stimuli - 'Animals','Plants' and 'Humans', respectively. GO trials are when A-A stimuli require the subject to press a button. NOGO trials are A-P stimuli, which require suppression of a prepared action. GO and NOGO trials represent 'Continue set' in which subjects have to prepare for action after the first stimulus presentation (A). Ignore trials are stimuli pairs beginning with a $\mathrm{P}$, which require no preparation for action. Novel trials are pairs requiring no action, with presentation of a novel sound as the second stimuli. Ignore and Novel trials represent the 'Discontinue set', in which subjects do not need to prepare for action after the first stimulus presentation. Time intervals are depicted at the bottom

The trials consisted of presentations of paired stimuli with inter-stimulus intervals of $1 \mathrm{~s}$. The duration of stimuli was $100 \mathrm{~ms}$. Four categories of trials were used (Fig. 2): A-A, A-P, P-P, and P-(H+Sound). The trials were grouped into 4 blocks of 100 trials each. In each block, a unique set of $5 \mathrm{~A}$, $5 \mathrm{P}$, and $5 \mathrm{H}$ stimuli were selected. The patient practiced the task before the recording started.

The patient sat upright in an easy chair looking at a computer screen. The task was to press a button with the right hand in response to all A-A pairs as fast as possible, and to withhold pressing the button in response to other pairs: A-P, P-P, P-(H+Sound) (Fig. 1). According to the task design, 2 preparatory sets were distinguished: 'Continue set', in which $\mathrm{A}$ is presented as the first stimulus and the subject is presumed to prepare to respond; and 'Discontinue set', in which $\mathrm{P}$ is presented as the first stimulus, and the subject does not need to prepare to respond. In the 'Continue set', A-A pairs are referred to as 'GO trials', A-P pairs as 'NO GO trials'. Averages for response latency and response variance across the trials were calculated. Omission errors (failure to respond in GO trials) and commission errors (failure to suppress a response to NO GO trials), were also computed.

EEGs were recorded from 19 scalp sites. The electrodes were applied according to the International 10-20 system. The EEG was recorded referentially to linked ears, allowing computational re-referencing of the data (remontaging).

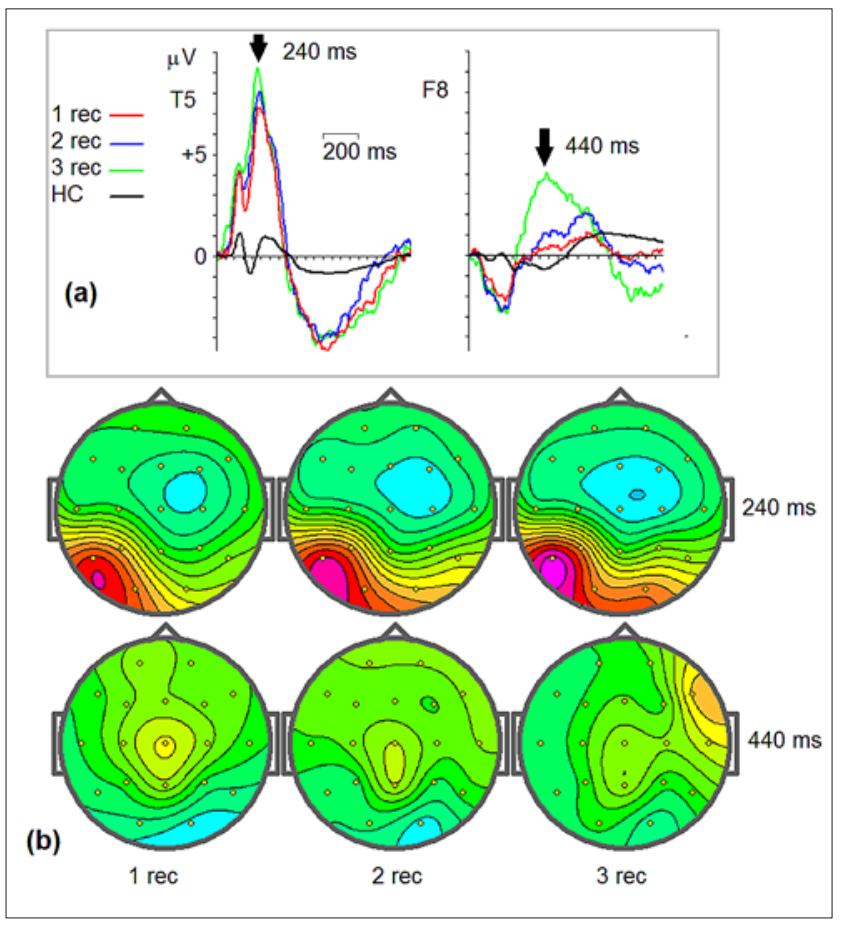

Figure 4. Event-related potentials (ERPs) in the cued GO/NOGO task. (a) ERPs in response to the relevant cue (animal) at the first position of the trial in the subject for the 3 recordings (red, blue and green, correspondingly), compared to the grand average ERPs in the group of healthy control subjects $(\mathrm{N}=34)$ of the same age (black). Arrows indicate the times at which maps were made. (b) Maps of ERPs at the two times for the three recordings

Figure 4 shows ERPs in relation to the relevant cue (first stimulus in pairs started with the presentation of 'Animal') for the first, second and third recordings, compared to the controls). As can be seen, a large deviation from the reference (normative data of a group of healthy subject) is presented at the left temporal area. The deviation is expressed as an increase of the P1 and P2 components. The increase is accompanied by the disappearance of the N170 wave. There is a steady increase in these waves from the first to the second and third recordings. In addition to these changes at the left temporal area, a change in the right frontal area is found in the third recording.

Figure 5 represents sLORETA images corresponding to peak performance amplitude of the potential recorded at the T5 electrode. As can be seen, the location of the maximum of current density remained within the Brodmann's area 39, but shifted frontally during the final recording.

\section{DISCUSSION}

In the subject literature there are a few reports dedicated to the treatment of patients with post-traumatic crossed aphasia (30, 31). This is the case also with aphasia in the world literature, and although much attention has been devoted to the topic of crossed aphasia in dextrals (CAD) over the past century, there is still no theory to explain the anomalous organization of neurocognitive functions, although it is thought that this is a genetic issue, one connected with the handedness in this population. However, if strict selection criteria are applied, only some cases of vascular CAD are reported in which the correlation between neurocognitive disturbances and the locus of the brain lesion is observed. Mariën et al. 


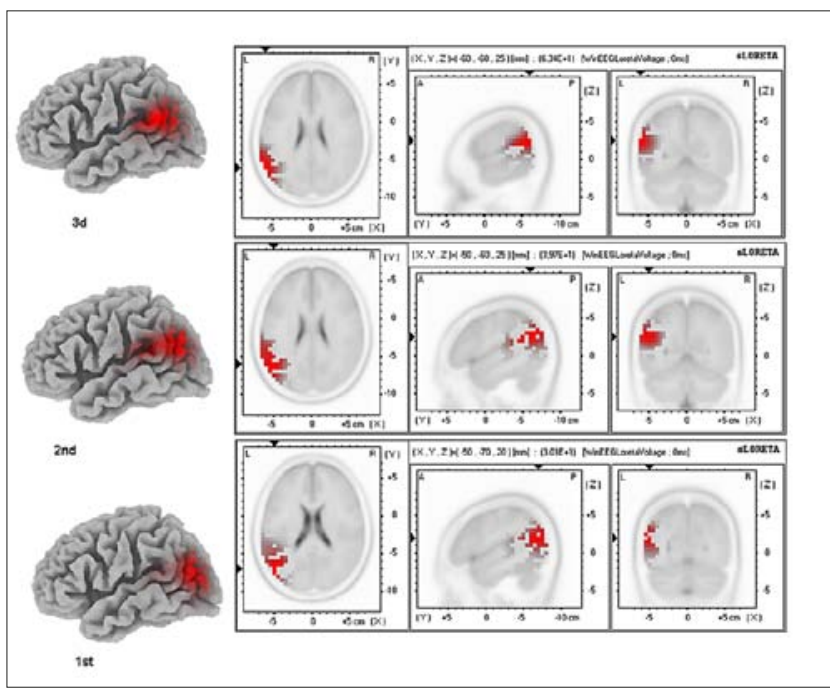

Figure 5. sLORETA images for the ERPs taken at maximum amplitude at the T5 electrode for the first, second and third recordings

(31) tested in-depth neurolinguistic and neuropsychological investigations and described nine new cases of vascular CAD. They showed the semiological variability of the CAD phenomena, and the many facets of the lesion-behaviour relationships of this exceptional neurobiological condition. Even such testing is not helpful in the administration of the proper therapeutic programmes for those patients. In the presented case, the patient, who did not have effective aphasia treatment, this was to become a chronic state. Therefore, it was decided to introduce, on the basis of the application of ERPs, neuromarkers for the assessment and experimental treatment of this patient with chronic crossed aphasia after severe TBI and a long-term coma.

In the case of neurofeedback in TBI patients, quantitative electroencephalography (qEEG) patterns are assessed and then compared with a database obtained from a normative population [21]. Deviations in the qEEG patterns from the normative group form the basis for an intervention plan [25]. The deficiency of relative beta EEG activity found in the presented TBI patient prompted the suggestion of relative beta neurofeedback training for her.

In the $1^{\text {st }}$ recording, before the experiment, the neuromarker of aphasia - excess P2 wave was found that over the left temporal area, which can be explained by an increase in the sensitivity of neurons near the area of the cortical damage. This phenomenon, in turn, can be attributed to an increase in excitatory post-synaptic potentials, and the removal of inhibition from the neurons located near the infarct.

Additionally, there was the patient's cognitive control deficit - the excess of omission errors and increase of RT variability - all indexes of ADHD. The decision was made to make a protocol to improve the cognitive control by the relative beta neurofeedback. This methodology was effective and, after the neurofeedback sessions, in the $2^{\text {nd }}$ recording, the largest improvements in cognitive control were found. An improvement was also observed in her behaviour. However, there was still a lot of agramatism in the frontal syndrome which was not beneficial for her daily functioning, and resulted in the decision to activate the right hemisphere by rTMS $(5 \mathrm{~Hz})$, and to inhibit the left hemisphere $(1 \mathrm{~Hz})$.

After the rTMS sessions, the neuromarker of aphasia did not change, only the location slightly moved frontally, but activation (an increase in the ERP) was observed over the right frontal lobe. It appears that this method helps to obtain a big improvement in aphasia behaviourally. This could be interpreted as a compensatory role of the right frontal cortex.

The patient's training was intended to activate the hypofunctioning frontal lobes by means of self-regulation, using the EEG neurofeedback parameter (the relative beta EEG power) as an index of hypofrontality. It should be stressed here that neurofeedback alone did not have any significant effect on either the neuropsychological or neurophysiological parameters of the brain functioning in this patient, as reflected in the neuropsychological and neurophysiological parameters recorded after 20 sessions of neurofeedback.

Two non-invasive methods of injecting electrical currents into the brain have proved to be promising for inducing long-lasting plastic changes in the motor systems. They are transcranial magnetic stimulation (TMS) [32 - 35] and transcranial direct current stimulation (tDCS) [29]. These techniques represent powerful methods for priming cortical excitability in subsequent motor or cognitive training. Thus, their combined use can optimize the plastic changes induced by motor-cognitive practice, leading to more remarkable and long-lasting clinical gains in rehabilitation [28].

TMS is delivered to the brain by passing a strong yet brief electrical current through an insulated wire coil placed on the skull. The current generates a transient magnetic field which, in turn, induces a secondary current in the brain that is capable of depolarising neurons [27]. Depending on the frequency and duration of the stimulation, the shape of the coil and the strength of the magnetic field, TMS can stimulate or suppress activity in the cortical regions [28].

tDCS delivers weak polarizing direct currents to the cortex via 2 electrodes placed on the scalp: an active electrode is placed on the site overlying the cortical target, and a reference electrode is usually placed over the contralateral supraorbital or mastoid area. $\mathrm{tDCS}$ acts by inducing sustained changes in the neural cell membrane potential - cathodal tDCS leads to brain hyperpolarization (inhibition), whereas anodal results in brain depolarization (excitation) [29].

TMS and tDCS employ different mechanisms of actions on the brain, with TMS acting as a neuro-stimulator and tDCS as a neuro-modulator. TMS has better spatial and temporal resolution, and its protocols are better established. tDCS has the advantage of being easier to use in double-blind or sham-controlled studies and easier to apply concurrently with behavioural tasks [29]. Despite their differences, both TMS and tDCS can induce long-term after-effects on cortical excitability that can last for months [31,32]. These long-term after-effects are believed to engage the mechanisms of neural plasticity, making these techniques ideally suited in the rehabilitation of strokes and TBI [33].

In presented case, in programme $\mathrm{A}$, relative beta training was applied, according to recent findings in the subject literature $[26,34]$, although it proved to be ineffective. The patient's attention did not improve which, generally, is a bad sign for recovery [35-39]. In programme B, however, rTMS was applied in order to activate the hypofunctioning areas of the frontal lobe. Ten sessions of rTMS appeared to produce clinically significant changes within the neuropsychological parameters, as well as statistically reliable changes in the physiological parameters of brain functioning. tDCS was not used, but on the basis of the subject literature, it can be 
suggested that a combination of brain stimulation techniques, such as TMS and tDCS, might have beneficial consequences for TBI patients.

\section{CONCLUSIONS}

The rTMS program produced greater physiological and behavioural changes than relative beta training in a patient with TBI and aphasia syndrome. A combination of different neurotherapeutical approaches (such as neurofeedback, rTMS, tDCS) can be suggested for similar severe cases with TBI and aphasia syndrome. ERPs can be used to assess the functional brain changes induced by neurotherapeutical programmes.

\section{REFERENCES}

1. McAllister TW, Neurobehavioral sequelae of traumatic brain injury: evaluation and management. World Psychiatry. 2008; 7(1): 3-10.

2. Yousefzadeh-Chabok S, Ramezani S, Reihanian Z, Safaei M, Alijani B, Amini N. The role of early posttraumatic neuropsychological outcomes in the appearance of latter psychiatric disorders in adults with brain trauma. Asian J Neurosurg. 2015; 10(3): 173-80.

3. Whyte J, Polansky M, Cavallucci C. Inattentive behavior after traumatic brain injury. J Int Neuropsychol Soc. 1996; 2: 274-281.

4. Ben-Yishay Y, Diller L. Cognitive remediation in traumatic brain injury: update and issues. Arch Phys Med Rehabil. 1993; 74: 204-213.

5. Cicerone K, Dahlberg C, Kalmar K. Evidence-based cognitive rehabilitation: recommendations for clinical practice. Arch Phys Med Rehabil. 2000; 81: 1596-1615.

6. McAllister TW. Neurobiological consequences of traumatic brain injury. Dialogues Clin Neurosci. 2011; 13(3): 287-300.

7. Lehtonen S, Stringer AY, Millis S. Neuropsychological outcome and community re-integration following traumatic brain injury: the impact of frontal and non-frontal lesions. Brain Inj. 2005; 19: 239-256.

8. Chantsoulis M, Mirski A, Rasmus A, Kropotov JuD, Pachalska M. Neuropsychological rehabilitation for traumatic brain injury patients. Ann Agric Environ Med. 2015; 22(2): 368-379. doi: 10.5604/12321966.1152097.

9. Mathias JL, Wheaton P. Changes in attention and informationprocessing speed following severe traumatic brain injury: a metaanalytic review. Neuropsychology. 2007; 21: 212-223.

10. Hart T, Whyte J, Millis S. Dimensions of disordered attention in traumatic brain injury: further validation of the Moss Attention Rating Scale. Arch Phys Med Rehabil. 2006; 87: 647-655.

11. Vakil E. The effect of moderate to severe traumatic brain injury (TBI) on different aspects of memory: a selective review. J Clin Exper Neuropsychol. 2005; 27: 977-1021.

12. Ruff RM, Levin HS, Mather S. Recovery of memory after mild head injury: a three center study. In: Levin HS, Eisenberg HM, Benton AL, editors. Mild head injury. New York: Oxford University Press; 1989. pp. 176-188.

13. O'Jile JR, Ryan LM, Betz B. Information processing following mild head injury. Arch Clin Neuropsychol. 2006; 21: 293-296.

14. Rassovsky Y, Satz P, Alfano MS. Functional outcome in TBI. Verbal memory and information processing speed mediators. J Clin Exper Neuropsychol. 2006; 28: 581-591.

15. Ewing-Cobbs L, Barnes M. Linguistic outcomes following traumatic brain injury in children. Semin Pediatr Neurol. 2002; 9: 209-217.

16. Weintraub S, Mesulam MM, Kramer L. Disturbances in prosody. A right-hemisphere contribution to language. Arch Neurol. 1981; 38: $742-744$.

17. Pąchalska M, Kaczmarek BLJ, Kropotov JD. Neuropsychologia kliniczna: od teorii do praktyki. Warszawa: Wydawnictwo Naukowe PWN. 2014.

18. Mauritz W, Wilbacher I, Majdan M, Leitgeb J, Janciak I, Brazinova A, Rusnak M. Epidemiology, treatment and outcome of patients after severe traumatic brain injury in European regions with different economic status. Eur J Public Health. 2008; 18(6): 575-80.

19. Benedictus MR, Spikman JM, van der Naalt J. Cognitive and behavioral impairment in traumatic brain injury related to outcome and return to work. Arch Phys Med Rehabil. 2010; 91(9): 1436-41.

20. Tomaszewski W, Buliński L, Mirski A, Rasmus A, Kowalczyk J, Bazan M, Pachalska M. An evaluation of anti-social behaviour in children after traumatic brain injury - prospects for improving the quality of life in rehabilitation. Ann Agric Environ Med. 2014; 21(4): 649-653. doi: 10.5604/12321966.1120620.

21. Pachalska M. Neuropsychologia kliniczna: urazy mózgu. Warszawa: Wydawnictwo Naukowe PWN. 2014.

22. Półrola P, Kaczmarek BLJ, Góral-Półrola J, Kropotov JD, Sucharska I, Pąchalska M. Event-related potential studies of combined Mild Traumatic Brain Injury/Post-Traumatic Stress Disorder in a retired Polish Army Lieutenant Colonel. Acta Neuropsychologica 2016; 14(1): 69-91. doi: 10.5604/17307503.1184047.

23. Duff J. The usefulness of quantitative EEG (QEEG) and neurotherapy in the assessment and treatment of post-concussion syndrome. Clin EEG Neurosci. 2004; 35(4): 198-209.

24. Trystuła M, Zielińska J, Półrola P, Goral-Połrola J, Kropotov ID, Pachalska M. Neuromarkers of anxiety in a patient with suspected schizophrenia and TIA: the effect of individually-tailored neurofeedback. Acta Neuropsychologica 2015; 13(4): 395-404.

25. Pascual-Leone A, Walsh V, Rothwell J. Transcranial magnetic stimulation in cognitive neuroscience - virtual lesion, chronometry, and functional connectivity. Current Opinion in Neurobiology 2000; 10(02): 232-237.

26. Rao V, Rosenberg P, Bertrand M, Salehinia S, Spiro J, Vaishnavi S, Rastogi P, Noll K, Schretlen DJ, Brandt J, et al. Aggression after traumatic brain injury: prevalence and correlates. J Neuropsychiatry Clin Neurosci. 2009; 21(4): 420-9.

27. Milders M, Ietswaart M, Crawford JR, Currie D. Social behavior following traumatic brain injury and its association with emotion recognition, understanding of intentions, and cognitive flexibility. J Int Neuropsychol Soc. 2008; 14(2): 318-26.

28. Pachalska M, Moskała M, MacQueen BD, Polak J, Wilk-Frańczuk M. Early neurorehabilitation in a patient with severe traumatic brain injury to the frontal lobes. Med Sci Monit. 2010; 16(12): CS157-67.

29. Kropotov JD. Quantitative EEG, Event Related Potentials and Neurotherapy. 2009; Academic Press, Elsevier, San Diego, 542 p.

30. Pachalska M. Rehabilitacja neuropsychologiczna [Neuropsychological Rehabilitation]. Lublin 2008, Wydawnictwo UMCS.

31. Mariën P, Engelborghs S, Vignolo LA, De Deyn PP. The many faces of crossed aphasia in dextrals: report of nine cases and review of the literature. European Journal of Neurology 2001; 8(6): 634-658.

32. Meinzer M, Harnish S, Conway T, Crosson B. Recent developments in functional and structural imaging of aphasia recovery after stroke. Aphasiology. 2011; 25(3): 271-290.

33. Pascual-Leone A, Walsh V, Rothwell J. Transcranial magnetic stimulation in cognitive neuroscience - virtual lesion, chronometry, and functional connectivity. Current Opinion in Neurobiology 2000; 10(02): 232-237.

34. Nitsche MA, Doemkes S, Karakose T, Antal A, Liebetanz D, Lang N, Tergau F, Paulus W. Shaping the effects of transcranial direct current stimulation of the human motor cortex. J Neurophysiol. 2007; 97: 3109-3117.

35. Kropotov JD, Grin-Yatsenko VA, Ponomarev VA, Chutko LS, Yakovenko EA, Nikishena IS. ERPs correlates of EEG relative beta training in ADHD children. Int J Psychophysiol. 2005; 55(1): 23-34.

36. Zielińska J, Góral-Półrola J, Półrola P, Łuckoś M, Kropotov JD, Pąchalska M. Hyper-frontality in an OCD patient - evidence from event-related potentials in a cued GO/NOGO task. Ann Agric Environ Med. 2016; 23(2): 276-279. doi: 10.5604/12321966.1203890

37. Pape TL, Rosenow J, Lewis G. Transcranial magnetic stimulation: a possible treatment for TBI. J Head Trauma Rehabil. 2006; 21(5): 437-451.

38. Bashir S, Mizrahi I, Weaver K, Fregni F, Pascual-Leone A. Assessment and modulation of neural plasticity in rehabilitation with transcranial magnetic stimulation. PM R. 2010; Suppl 2: 253-268.

39. Bolognini N, Pascual-Leone A, Fregni F. Using non-invasive brain stimulation to augment motor training-induced plasticity. Neuroeng Rehabil. 2009; 6-8. 